\title{
SYNERGISTIC EFFECT OF SOME PLANT EXTRACTS AND ANTIBIOTIC DRUGS AGAINST STAPH. AUREUS ISOLATED FROM PLEURAL FLUID IDENTIFICATION OF THE ACTIVE COMPOUNDS
}

\author{
Asmaa F. Hussein ${ }^{1}$; Rawia F. Gamal' ${ }^{1}$ A.A. Refaat ${ }^{1}$; A.F. Abdel-Salam ${ }^{2}$ \\ and K.M.A. Ramadan ${ }^{3}$ \\ 1- Agricultural Microbiology Dept., Faculty of Agriculture, Ain Shams University, Cairo, Egypt \\ 2- Bacterial Contamination Dept., ARC, Giza, Egypt \\ 3- Biochemistry Dept., Faculty of Agriculture, Ain Shams University, Cairo, Egypt
}

Keywords: S.aureus, Antibiotics, Phytoextract, Synergistic effects, MBC, 16S rRNA, GC-MS spectrometry

\section{ABSTRACT}

A total of 75 pyogenic samples were collected from patients examinated for pyogenic infection in Sednawy hospital and Elmokhtaber laboratories. $S$. aureus isolated from pleural fluid out of five $S$. aureus (+ve coagulase, MSSA) exhibits resistant against all the concentration of Ciprofloxacin 0.520, Gentamycin 0.5- $5.0 \mu \mathrm{g} / 100 \mu \mathrm{l}$ and Amikacin 1 $\mu \mathrm{g} / 100 \mu \mathrm{l}$. The highest potent of phytoextracts either extracted by water or methanol was detected by clove comparing with mint, thyme, sage and garlic, whereas garlic essential oil gave completely abolish of $S$. aureus (P.F). The highest synergism was obtained in combination between the lowest inhibitory concentration of Gentamycin $10 \mu \mathrm{g} / 100 \mu \mathrm{l}$ or Vancomycin $1 \mu \mathrm{g} / 100 \mu \mathrm{l}$ or Amikacin 2.5 $\mu \mathrm{g} / 100 \mu \mathrm{l}$ with thyme Eso $(1: 3)$, which resulted to increase the efficacy by 4.4 or 1.5 or 1.6 respectively comparing to recommended dose of the tested antibiotics alone. Increasing the concentration of garlic essential oil (GEso) from 10 up to 100 $\mu \mathrm{l} /$ well increment the efficacy of inhibition up to 10 , 3.7 and 4.5- fold when standard dose of Gentamycin, Vancomycin and Amikacin were used individually against $S$. aureus P.F. The minimum bactericidal concentration of garlic essential oil was recorded at $2 \mu \mathrm{l} / \mathrm{ml}$ as it resulted to reduce the count to be $0.04 \%$. Analysis of garlic essential oil by GCMS dedicated six sulfur compounds represented $88.8644 \%$ of total detected compounds in garlic essential oil.

\section{INTRODUCTION}

Antimicrobial agents produced by plants are active against plant, human and animal pathogens. The use of plant extracts and phytochemicals, both with known antimicrobial properties, can be of great significance in therapeutic treatments. According to $\mathrm{WHO}$, medicinal plants would be the best source to obtain a variety of drugs and herbal medicines serve the health needs of about $80 \%$ of the world's population, especially for millions of people in the vast rural areas of developing countries (WHO, 2001). Therefore, such plants should be investigated to better understand their properties, safety and efficiency. In recent years, different reports, from different countries were published showing the antimicrobial activities of medicinal plants include studies of medicinal plants from Greece (Proestos et al 2006), Palestine (AbuShanab et al 2006), Lebanon (Barbour et al 2004) Turkey (Uzun et al 2004), Ethiopia (Tadeg et al 2005), Iran (Bonjar, 2004) and India (Nair et al 2005).

S. aureus can cause a range of illnesses, from minor skin infections, such as pimples, impetigo, boils (furuncles), cellulitis folliculitis, carbuncles, scalded skin syndrome, and abscesses, to lifethreatening diseases such as pneumonia, meningitis, osteomyelitis, endocarditis, toxic (TSS), bacteremia, and sepsis. Its incidence ranges from skin, soft tissue, respiratory, bone, joint, endovascular to wound infections. It is still one of the five most common causes of nosocomial infections and is often the cause of postsurgical wound infections. (Huggan et al 2008 and Marioara et al 2009). 
This work aimed to investigate the most effective antibiotic against pathogenic $S$. aureus and also the antibacterial activities of some plant extracts in addition the effect of combination ratios between lowest concentration of antibiotic and phytoextract on $S$. aureus . Identified the effective compared in the most effective plant use GC-MS.

\section{MATERIALS AND METHODS}

\section{Samples}

Seventy five clinical specimens were randomly collected at the period from June to October 2014; from the patients attending the out clinics of Sednawy hospital and Al-Mokhtabar laboratories. These specimens include boils and abscess in face (30), tumor in breast (15), pleural fluid (15) and wound swaps (15).

\section{Media used}

- Baird Parker medium and Blood agar medium (Baird-Parker, 1962) were used for isolation and enumeration of coagulase-positive staphylococci.

- Brain heart infusion broth (BHI) (Greenberg et al 1995) was used as enrichment media.

- Biochemical reactions: were carried out according to APHA, 1992 (Catalase activity test), Cappuccino and Sherman 1996 (Mannitol fermentation) and Mackie and McCartney 1996 (Coagulase test).

- Detection of MRSA (methicillin -resistant strain) or MSSA (methicillin -sensitive strain, were carried out according to Koneman et al (1997).

Biofilm production of investigated $S$. aureus isolate was performed using micro titer plate (MtP) assay according to Christensen et al (1982) and Hossain and Uddin, (2014).

Antibiotics used: Gentamycin, ciprofloxacin, Vancomycin, Amikacin, Oxicillin and Cefoxitine

Plants used: Floral buds of clove (Syzygium aromaticum), Grass and leaves of mint (Mentha piperita), Grass of thyme (Thymus vulgaris), Lobes of Garlic (Allium sativium) and Leave \& stems of Sage (Salvia officinalis).

\section{Preparation of plant extracts}

Aqueous and Solvent (methanol) extractions were procedure according to Parekh et al (2005). The essential oils of the used plants were prepared by extraction and aromatic oil unit in National Research Center (NRC).
Antibacterial activity of Antibiotic or plant extracts by well diffusion method

Antibacterial activity of antibiotics or plant extracts was determined by the well diffusion method according to NCCLS, (1993). Petri plates containing $25 \mathrm{ml}$ of Muller Hinton agar medium (Mueller and Hinton, 1941) were inoculated with $1 \mathrm{ml}$ standard inoculums $\left(20 \times 10^{8} \mathrm{CFU} / \mathrm{ml}\right)$ of $S$. aureus (P.F). Agar wells were made by using sterile cork borer (7 mm diameter). Each well was filled with $100 \mu \mathrm{l}$ of the tested plant extract or antibiotic and the plates were incubated at $37^{\circ} \mathrm{C}$ for $24 \mathrm{~h}$. All tests were performed in duplicate and the antibacterial activity was expressed as the mean diameter of inhibition zones (mm). Methanol (99\%) was tested against the $S$. aureus as a control.

\section{Minimal inhibitory concentration assay (MIC)}

The extracts that showed antibacterial activity were tested to determine the minimal inhibitory concentration (MIC) for bacterial sample. The bacterial sample $S$. aureus was grown in nutrient broth for $24 \mathrm{~h}$ then $200 \mu \mathrm{L}$ of $20 \times 10^{8} \mathrm{CFU} / \mathrm{ml}$ was inoculated in tubes with nutrient broth supplemented with different concentrations $(1-10 \mu \mathrm{l} / 100 \mu \mathrm{l})$ of the garlic Eso. Afterwards $24 \mathrm{~h}$ at $37^{\circ} \mathrm{C}$, the MIC of each sample was determined by measuring the optical density in the spectrophotometer $(620 \mathrm{~nm})$, comparing the sample readout with the noninoculated nutrient broth. The MICs were determined as the lowest concentration of garlic Eso inhibition visible growth of the lasted culture on the agar plate (Mahdi et al 2013).

\section{Determination of minimal bactericidal concen- tration (MBC)}

Based on the results of the MIC assay, essential oil of garlic that showed a high level of bacterial inhibition were used for determination MBC by using broth dilution method reported by Davidson and Parish (1989) with some modifications as follows: before autoclaving media (Nutrient broth), a $2 \%(v / v)$ tween 80 (Scharlau Chemie) was added in order to facilitate dispersion of the Eso. Lambert et al (2001) reported that MIC or MBC are affected by the dispersion agent used, and that their values be lower if this agent is absent. The experiment was performed by adding bacterial suspension at a concentration of $20 \times 10^{8} \mathrm{CFU} / \mathrm{ml}$ and garlic Eso with a final concentrations $1-10 \mu \mathrm{l} / 100 \mu \mathrm{l}$, each tube containing $1000 \mu \mathrm{l}$ of sterile nutrient broth with $2 \%$ 

Isolated From Pleural Fluid Identification of the active compounds

tween 80 . The control was prepared using the medium with $2 \%$ tween 80 without Eso were incubated at $37^{\circ} \mathrm{C}$ for $24 \mathrm{hr}$. A $100 \mu \mathrm{l}$ aliquot was spread on bard parker plates and nutrient broth in order to determine bacterial count and optical density at $620 \mathrm{~nm}$. the lowest concentration of garlic Eso or compound resulted in a viable count of less than $0.1 \%$ of the original inoculum $(\mathrm{CFU} / \mathrm{ml})$ considered $\mathrm{MBC}$ as compared to the turbidity of the McFarland 0.5 standard (NCCLS, 2008)

Polymerase chain reaction (PCR) and sequencing of $S$. aureus isolate from pleural fluid

It's carried out by Molecular Genetic laboratory (Rashid's lab), Genetics department, Faculty of Agriculture, Ain - shams University.

\section{GC-MS analysis of garlic essential oil}

GC-MS spectrometry analyses were performed on a gas chromatograph Agilent technology 7890B GC system equipped with an DB-5MS (30 m - ID $0.25 \mathrm{~mm}$ - Film thickness 0.1 micro meter) and interfaced with an Agilent 5977A MSD mass selective detector. The oven temperature was programmed at $40^{\circ} \mathrm{C}$ (3 minute) to $280^{\circ} \mathrm{C}$ at $50^{\circ} \mathrm{C} /$ minute and held isothermally for 5 minutes. Ionization mode was electron impact (EI) $(70 \mathrm{eV})$, with scan range 40-650 amu and scan time 1.5 seconds. inlet pressure $7.38 \mathrm{psi}$, injector temperature $280^{\circ} \mathrm{C}$, detector temperature $280^{\circ} \mathrm{C}$ and split ratio $1: 10$. Nitrogen was used as carrier gas at a flow rate of $2 \mathrm{~mL} /$ minute. Identification of the essential oil components was based on the molecular mass of compounds. All mass spectra were compared with the data system libraries (Nist05a.L, Wiley 7Nist0.5. L), and other published spectra, Adams (2001), as well as by comparison of their retention index with data from the mass spectral library 'Terpenoids and Related Constituents of Essential Oils' (Dr Detlev Hochmuth) using then Mass Finder 3 software (http://www.massfinder.com).

\section{RESULTS AND DISCUSSION}

Antibacterial activity of different concentration of antibiotics $(\mu \mathrm{g} / 100 \mu \mathrm{l})$ against $S$. aureus (Pleural fluid)

Four selected antibiotics namely Gentamycin, Ciprofloxacin, Vancomycin and Amikacin were tested for their antibacterial activity against $S$. aureus isolated from Pleural fluid (coagulase positive,
MSSA and unable to form biofilm). It is apparent from illustrated data by Fig. (1), that there is great variation of sensitivity toward the tested antibiotics, the isolate exhibits resistant against all the concentrations of Ciprofloxacin 0.5-20, Gentamycin 0.5$5.0 \mu \mathrm{g} / 100 \mu \mathrm{l}$ and Amikacin $1 \mu \mathrm{g} / 100 \mu \mathrm{l}$. It's worthy of note that the MIC of Gentamycin and Amikacin were 10 and $2.5 \mu \mathrm{g} / 100 \mu \mathrm{l}$ respectively, as no inhibition zone could be detected on agar well diffusion method at lower concentrations. The resistance of $S$. aureus (P.F) against Ciprofloxacin may be due to the increased use of Ciprofloxacin which resulted to development of their resistance Derrida, (2003).

Antibacterial activity of some phytoextracts by different methods on the viability of the $S$. aureus (P.F).

The results of the antibacterial screening assay of the crude extracts of the tested plants are shown in Fig. (2). It is apparent from the illustrated data that the highest potent of phytoextracts either extracted by water or methanol was detected by clove comparing with mint, thyme, sage and garlic, whereas garlic essential oil gave completely abolish of $S$. aureus (P.F). As can be seen from the results, clove is the most active medicinal plants of $S$. aureus. The other phytoextracts included in the present study were also found to be active on at least one of the extract type (aqueous, methanol or essential oil). These results are coincides with those obtained by Bayoub et al (2010) who reported that the antibacterial activity of clove ethanolic extract has been attributed to the presence of some active constituents in the ethanol extracts.

The data also presented in Fig. (2) clearly show that thyme and sage methanolic extracts were active against the isolate. These results may be due to that the active substances were more soluble in organic solvents and, therefore not present in water extracts. The obtained data are in line with those obtained by De Boer et al (2005). Also Ali and Aboud (2010) reported that Methanol extracts of Salvia officinalis have had higher solubility for more phytoconstituents, consequently the highest antibacterial activity. All aqueous extracts of the tested plants were inactive against of $S$. aureus (P.F) except clove. This results are agreement with De Boer et al (2005) and Nzeako et al (2006) who stated that aqueous extracts showed less activity than ethanol extracts possibly because: 


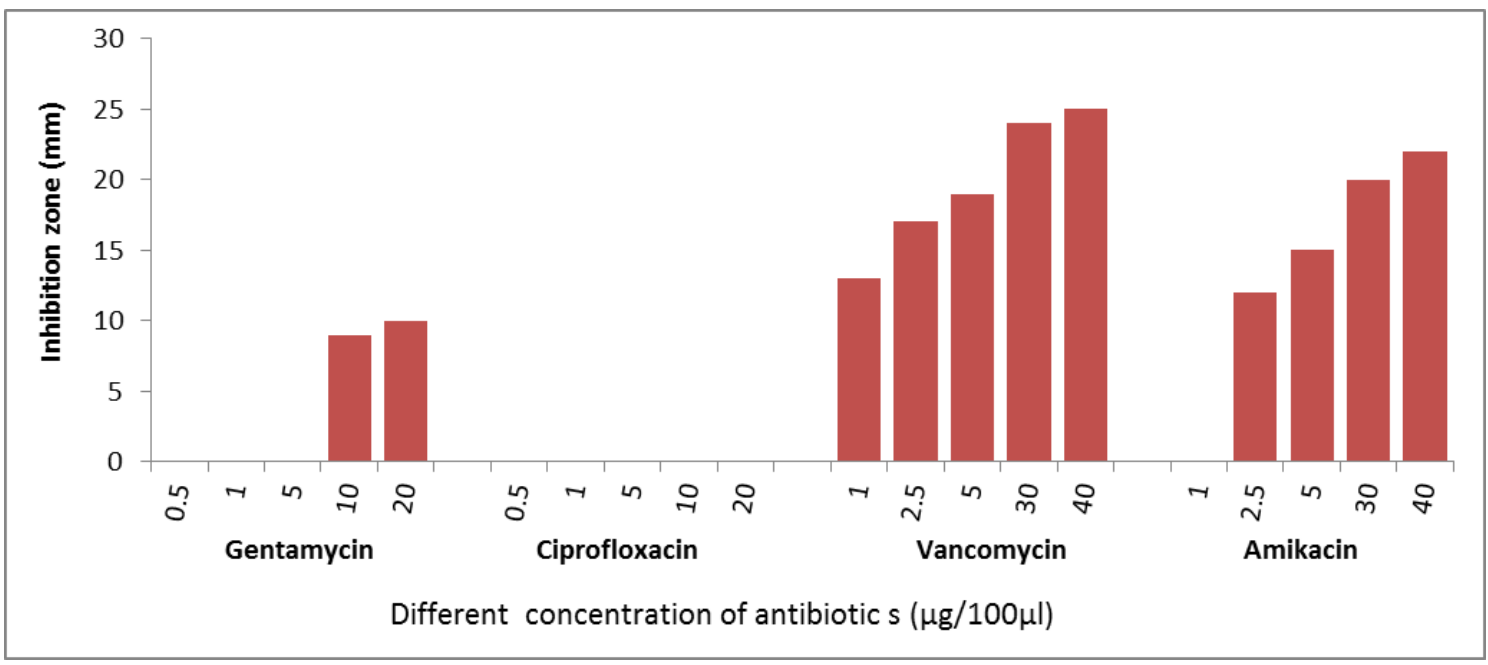

Fig. 1. Antimicrobial activity of different concentration of antibiotics ( $\mu \mathrm{g} / 100 \mu \mathrm{l})$ against $S$. aureus (P.F) isolate express as inhibition zone $(\mathrm{mm})$.

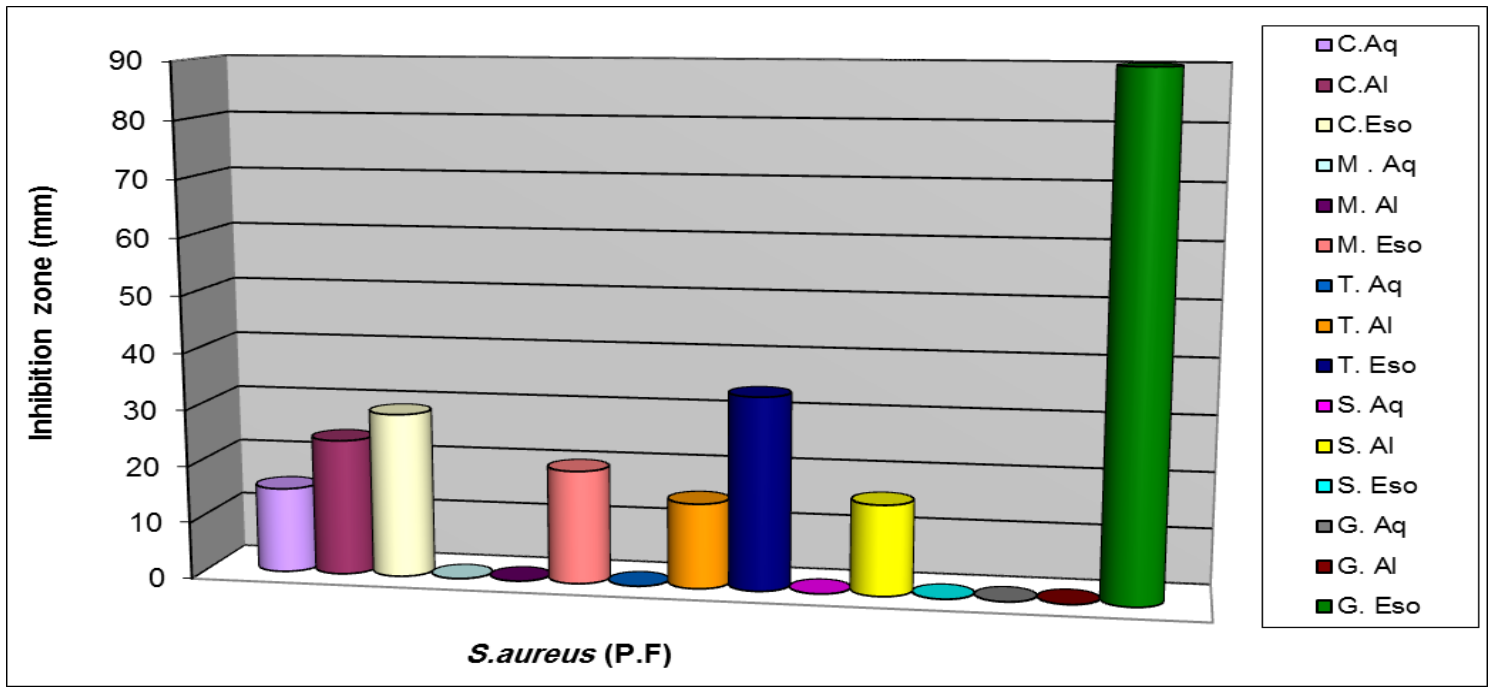

C.Aq: clove. Aqueous, C.Al: clove. Alcohol, C.Eso: clove essential oil, M.Aq: mint. Aqueous, M.Al: mint. Alcohol, M.Eso: mint essential oil, T.Aq: thyme. Aqueous, T.Al: thyme. Alcohol, T.Eso: thyme essential oil, S.Aq: sage. Aqueous, S.Al: sage. Alcohol, S.Eso: sage essential oi, G.Aq: garlic. Aqueous, G.Al : garlic. Alcohol, G.Eso: garlic essential oil

Fig. 2. Antibacterial activity of some phytoextracts by different methods on the viability of the isolated $S$. aureus (P.F) express as zone inhibition ( $\mathrm{mm})$. 
1) The same active substances were present in water extracts, but in lower concentrations.

2) Active substances were more soluble in organic solvents and, therefore, not present in water extracts.

In this study, sage essential oil was inactive against $S$. aureus (P.F) isolate. This results are contrast with Monika et al (2015), who showed that the Salvia sclarea essential (sage) oil has the strong anti-staphylococcal activity against clinical strains isolated from wound infections.

Efficacy of synergism (expressed as folds) between the lowest inhibitory concentration of the antibiotic with different ratios of plant extracts against $S$. aureus (P.F) comparing to phytoextract or standard dose of antibiotics

Our results present in Tables (1-3) clearly showed that combination between Gentamycin (10 $\mu \mathrm{g} / 100 \mu \mathrm{l})$ and essential oil of thyme at ratio $1: 3$, gave the highest efficiency against $S$. aureus (P.F), inhibition being 4.4 fold related to recommend concentration of Gentamycin $(10 \mu \mathrm{g} / 100 \mu \mathrm{l})$ alone. Whereas, it's gave 1.5 and 1.6 fold in combination between Vancomycin $(1 \mu \mathrm{g} / 100 \mu \mathrm{l})$ and Amikacin $(2.5 \mu \mathrm{g} / 100 \mu \mathrm{l})$ respectively against the same isolate. This implies that the essential oil of thyme increased the antibacterial activity against the tested isolate, and showed synergistic interaction against $S$. aureus (P.F).

Generally, it could be noticed that the essential oils of clove, and mint gave variation in figures being $2.3,3.1 \& 0.8,1.3 \& 1.0,1.3$ fold comparing with recommended concentration of Gentamycin $(10 \mu \mathrm{g} / 100 \mu \mathrm{l})$, Vancomycin $(30 \mu \mathrm{g} / 100 \mu \mathrm{l})$ and Amikacin $(30 \mu \mathrm{g} / 100 \mu \mathrm{l})$ alone respectively.

As regards to the efficacy of phytoextract by methanol, the presented data revealed that it depends on the used antibiotic, since it gave 1.8, 1.4, and 1.8 fold of inhibition against $S$. aureus (P.F) by using methanolic extract of clove, thyme and sage respectively by comparing with recommended concentration of Gentamycin $(10 \mu \mathrm{g} / 100 \mu \mathrm{l})$. On the contrary, all the data related to Vancomycin and Amikacin were reduced which implied that there is no synergistic interaction could be detected between them.

The combination between lowest inhibitory concentration of Gentamycin $(10 \mu \mathrm{g} / 100 \mu \mathrm{l})$ and clove extract by aqueous with ratio of $1: 3$ enhanced the inhibition of $S$. aureus (P.F) by 1.6 fold comparing with recommended concentration of Gentamycin $(10 \mu \mathrm{g} / 100 \mu \mathrm{l})$. Whereas, no synergistic interaction could be detected in a combination with Vancomycin $(1 \mu \mathrm{g} / 100 \mu)$ or Amikacin $(2.5 \mu \mathrm{g} / 100 \mu \mathrm{l})$.

In this study, synergism effect resulting from the combination of antimicrobial agents with essential oil were verified for all plants. In vitro studies Braga et al (2005), Yang et al (2005) and Esimone et al (2006) have reported synergistic effects significant reduction in the MIC of the antibiotics, resulting for the combination of antibiotics in the different crude plant extracts against $S$. aureus strains.

In this study synergistic effect was observed against isolate $S$. aureus, during the association of antibiotics with methanolic extracts from clove (Syzygium aromaticum), thyme (Thymus vulgaris). These results were consistent with the results previously cited by Nascimento et al (2000) who repoted that a synergistic effect was observed against different bacterial species, during the association of antibiotics with ethanolic extracts from clove (Caryophyllus aromaticus), jambolan (Syzygyum joabolanum), pomegranate (Punica granatum) and thyme (Thymus vulgaris).Also, Gislene et al (2000) \& Gupta et al (2009) found that the growth of $S$. aureus was inhibited when clove water extracts were combined with all tested antibiotics. Darwish et al (2002) reported that plants showed synergistic interactions in combination with chloramphenicol, gentamicin, erythromycin and penicillin $\mathrm{G}$ against $S$. aureus.

Comparative studies between different concentrations of Garlic essential oil and standard concentration of effective antibiotics against $S$. aureus (P.F) expressed as efficacy fold

Data which illustrated by Fig. (3) revealed that there is a direct relationship between the concentration of GEO and their efficacy against $S$. aureus (P.F). Increasing the GEO concentration from $10 \mu \mathrm{l}$ to $100 \mu \mathrm{l} /$ well resulted to increment the efficacy from 2.2 to 10 , from 0.8 to 3.7 and from 1.0 to 4.5 fold comparing to recommended dose of Gentamycin, Vancomycin and Amikacin alone respectively against $S$. aureus.

Therefore, more serial dilutions of garlic essential oil were required in the following experiment in order to detect the minimum bactericidal concentration. From the experimental data, it could be stated that $2 \mu \mathrm{l} / \mathrm{ml}$ represent minimum bactericidal concentration of garlic essential oil which reduce the total viable count $\left(20 \times 10^{8} \mathrm{CFU} / \mathrm{ml}\right)$ to $0.04 \%$. These result was coinciding with NCCLS, (2008) which stated that the lowest concentration of a tested extract or compound resulted in a viable count of less than $0.1 \%$ of the original inoculum 
Table 1. Efficacy of synergism (expressed as folds) between the lowest inhibitory concentration of the antibiotic with different ratios of plant extracts against $S$. aureus (P.F) comparing to phytoextract or standard dose of Gentamycin

\begin{tabular}{|c|c|c|c|c|c|c|}
\hline \multirow{3}{*}{ Combination } & \multirow{3}{*}{ Type extracts } & \multirow{2}{*}{\multicolumn{3}{|c|}{$\begin{array}{l}\text { Inhibition zone of diameter } \\
\text { IZD (mm) } \\
\text { Gentamycin : phytoextract }\end{array}$}} & \multirow{2}{*}{\multicolumn{2}{|c|}{$\begin{array}{c}\text { Efficacy of G: P (1:3) } \\
\text { by fold to }\end{array}$}} \\
\hline & & & & & & \\
\hline & & 1:1 & $1: 2$ & $1: 3$ & Phytoextract & $\begin{array}{l}\text { Gentamycin } \\
(10 \mu \mathrm{g} / 100 \mu \mathrm{l}\end{array}$ \\
\hline Gentamycin+clove & Aqueous & $12 \pm 0.000$ & $13 \pm 0.333$ & $15 \pm 0.000$ & $1.0(15 / 15)$ & $1.6(15 / 9)$ \\
\hline Gentamycin+clove & Methanolic & $15 \pm 0.333$ & $16 \pm 0.333$ & $17 \pm 0.333$ & $0.7(17 / 24)$ & $1.8(17 / 9)$ \\
\hline Gentamycin+clove & Essential oil & $19 \pm 0.000$ & $20 \pm 0.000$ & $21 \pm 0.000$ & $1.4(21 / 29)$ & $2.3(21 / 9)$ \\
\hline Gentamycin+ mint & Essential oil & $20 \pm 0.000$ & $22 \pm 0.333$ & $28 \pm 0.000$ & $0.8(28 / 20)$ & $3.1(28 / 9)$ \\
\hline Gentamycin+thyme & Methanolic & $11 \pm 0.333$ & $12 \pm 0.000$ & $13 \pm 0.000$ & $1.1(13 / 15)$ & $1.4(13 / 9)$ \\
\hline Gentamycin+thyme & Essential oil & $28 \pm 0.000$ & $35 \pm 0.000$ & $40 \pm 0.000$ & $1.1(40 / 34)$ & $4.4(40 / 9)$ \\
\hline Gentamycin +sage & Methanolic & $13 \pm 0.000$ & $15 \pm 0.000$ & $17 \pm 0.000$ & $1.1(17 / 16)$ & $1.8(17 / 9)$ \\
\hline
\end{tabular}

The data given are mean $(n=3) \pm$ standard error

Table 2. Efficacy of synergism (expressed as folds) between the lowest inhibitory concentration of the antibiotic with different ratios of plant extracts against S. aureus (P.F) comparing to phytoextract or standard dose of Vancomycin.

\begin{tabular}{|c|c|c|c|c|c|c|}
\hline \multirow{3}{*}{ Combination } & \multirow{3}{*}{$\begin{array}{c}\text { Type } \\
\text { extracts }\end{array}$} & \multirow{2}{*}{\multicolumn{3}{|c|}{$\begin{array}{l}\text { Inhibition zone of diameter IZD } \\
(\mathrm{mm}) \text {. } \\
\text { Vancomycin : phytoextract }\end{array}$}} & \multirow{2}{*}{\multicolumn{2}{|c|}{ Efficacy of V: $P(1: 3)$ by fold to }} \\
\hline & & & & & & \\
\hline & & $1: 1$ & $1: 2$ & $1: 3$ & Phytoextract & $\begin{array}{l}\text { Vancomycin } \\
(30 \mu \mathrm{g} / 100 \mu \mathrm{l})\end{array}$ \\
\hline Vancomycin +clove & Aqueous & $13 \pm 0.000$ & $14 \pm 0.000$ & $15 \pm 0.000$ & $1.0(15 / 15)$ & $0.6(15 / 24)$ \\
\hline Vancomycin +clove & Methanolic & $16 \pm 0.000$ & $17 \pm 0.000$ & $19 \pm 0.666$ & $0.7(19 / 24)$ & $0.7(19 / 24)$ \\
\hline Vancomycin +clove & Essential oil & $18 \pm 0.333$ & $19 \pm 0.333$ & $20 \pm 0.333$ & $0.6(20 / 29)$ & $0.8(20 / 24)$ \\
\hline Vancomycin + mint & Essential oil & $20 \pm 0.000$ & $29 \pm 0.333$ & $32 \pm 0.333$ & $1.6(32 / 20)$ & $1.3(32 / 24)$ \\
\hline Vancomycin+thyme & Methanolic & $15 \pm 0.000$ & $16 \pm 0.333$ & $17 \pm 0.000$ & $1.1(17 / 15)$ & $0.7(17 / 24)$ \\
\hline Vancomycin+thyme & Essential oil & $27 \pm 0.000$ & $30 \pm 0.000$ & $36 \pm 0.333$ & $1.0(36 / 34)$ & $1.5(36 / 24)$ \\
\hline Vancomycin + sage & Methanolic & $16 \pm 0.333$ & $17 \pm 0.000$ & $18 \pm 0.000$ & $1.1(18 / 16)$ & $0.7(18 / 24)$ \\
\hline
\end{tabular}

The data given are mean $(n=3) \pm$ standard error 

Isolated From Pleural Fluid Identification of the active compounds

Table 3. Efficacy of synergism (expressed as folds) between the lowest inhibitory concentration of the antibiotic with different ratios of plant extracts against $S$. aureus (P.F) comparing to phytoextract or standard dose of Amikacin.

\begin{tabular}{|c|c|c|c|c|c|c|}
\hline \multirow{3}{*}{ Combination } & \multirow{3}{*}{ Type extracts } & \multirow{2}{*}{\multicolumn{3}{|c|}{\begin{tabular}{|c|} 
Inhibition zone of diameter IZD $(\mathrm{mm})$. \\
Amikacin : phytoextract \\
\end{tabular}}} & \multirow{2}{*}{\multicolumn{2}{|c|}{$\begin{array}{l}\text { Efficacy of } A: P(1: 3) \\
\text { by fold to }\end{array}$}} \\
\hline & & & & & & \\
\hline & & $1: 1$ & $1: 2$ & $1: 3$ & Phytoextract & $\begin{array}{c}\text { Amikacin } \\
(30 \mu \mathrm{g} / 100 \mu \mathrm{l})\end{array}$ \\
\hline Amikacin+clove & Aqueous & $13 \pm 0.000$ & $15 \pm 0.333$ & $17 \pm 0.000$ & $1.1(17 / 15)$ & $0.8(17 / 20)$ \\
\hline Amikacin+clove & Methanolic & $15 \pm 0.333$ & $16 \pm 0.333$ & $17 \pm 0.333$ & $0.7(17 / 24)$ & $0.8(17 / 20)$ \\
\hline Amikacin +clove & Essential oil & $19 \pm 0.000$ & $20 \pm 0.000$ & $21 \pm 0.33$ & $0.7(21 / 29)$ & $1.0(21 / 20)$ \\
\hline Amikacin + mint & Essential oil & $25 \pm 0.333$ & $26 \pm 0.333$ & $27 \pm 0.000$ & $1.3(27 / 20)$ & $1.3(27 / 20)$ \\
\hline Amikacin+thyme & Methanolic & $13 \pm 0.000$ & $14 \pm 0.333$ & $15 \pm 0.333$ & $1.0(15 / 15)$ & $0.7(15 / 20)$ \\
\hline Amikacin+thyme & Essential oil & $29 \pm 0.667$ & $31 \pm 0.333$ & $32 \pm 0.000$ & $0.9(32 / 34)$ & $1.6(32 / 20)$ \\
\hline Amikacin + sag & Methanolic & $17 \pm 0.333$ & $18 \pm 0.333$ & $19 \pm 0.333$ & $1.1(19 / 16)$ & $0.9(19 / 20)$ \\
\hline
\end{tabular}

The data given are mean $(n=3) \pm$ standard error

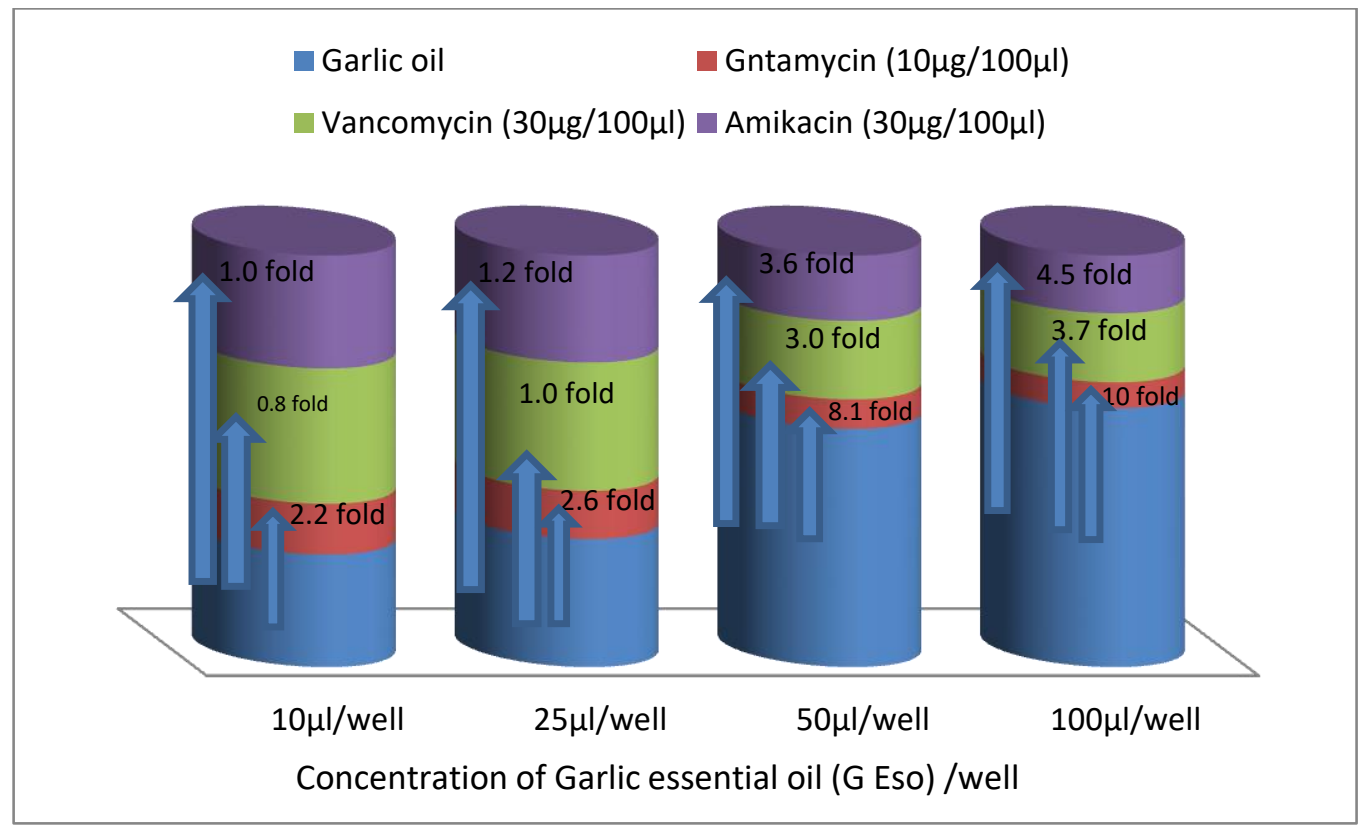

Fig. 3. Comparative studies between different concentrations of Garlic essential oil and standard concentration of effective antibiotics against $S$. aureus (P.F) expressed as efficacy fold. 
(CFU/ml) considered MBC as compared to the turbidity of the McFarland 0.5 standard. These recorded results in the present study could be explained on the light of what have been reported by other authors Mahady, (2001) \& Groppo et al (2002) and Alli et al (2011)) who have attributed the turbidity which reduced with the introduction and increase in concentration of the garlic extract was due to antimicrobial effect of the garlic extract on the tested organism.

Also, similar trend of garlic essential oil strength was found by Lemar et al (2005) and Eja et al (2007) who reported that allicin from garlic blocks the action of bacterial enzymes by reacting with this's thereby inhibiting the growth of the microbe. It could also be concluded from the findings of this study that the mode of action of garlic extract as an antibiotic is by affecting the nucleus (DNA or RNA synthesis).

\section{Molecular Identification of the S. aureus isolate}

16S rRNA sequence analysis is an important tool for identification of microbial species than morphological, physiological and biochemical characterization due to cumbersome and timeconsuming (Poorani et al 2009).

This method of identification is mainly based on the conserved 16S rDNA domains among bacterial speciesand being variable in certain regions that reflect it nature of being species specific. That, each species has a unique 16S rDNA sequence which reflects the validity of the test. In this method, the total genomic DNA was isolated, purified and used as a template for PCR amplification. The analysis of $16 \mathrm{~S}$ rRNA gene of $S$. aureus (PF) reveled the forward sequence (223 bp) and reverse sequence (243 bp) that was assembled to form a sequence of 272 bp length. CG\% was $51.9 \%$ with nucleotide frequencies of $\mathrm{T}=27.2 \%, \mathrm{C}=33.4 \%, \mathrm{G}$ $=18 \%$ and $\mathrm{A}=21.3 \%$.

\section{- Forward direction: 223 bp}

TTGGGCGTAAGCGCGCGTAGGCGGTTTTTTAAGTCTGATGTGAAAGCCCACGGCTCAACCGTGGAGGGTCATTGGAAACTGGAAAACTTGAGTGCAGAAGAGGAAAGTGGAATTCCATGTGTAG-
CGGTGAAATGCGCAGAGATATGGAGGAACACCAGTGGCGAAGGCGACTTTCTGGTCTGTAACTGACGCTGATGTGCGAAAGCGTGGGGATCAAACAGGA

- Reverse direction: 243 bp

CAGCGTCAGTTACAGACCAGAAAGTCGCCTTCGCCACTGGTGTTCCTCCATATCTCTGCGCATTTCACCGCTACACATGGAATTCCACTTTCCTCTTCTGCACTCAAGTTTTCCAGTTTCCAATGACCCTCCACGGTTGAGCCGTGGGCTTTCACATCAGACTTAAAAAACCGCCTACGCGCGCTTTACGCCCAATAATTCCGGATAACGCTTGCCACCTACGTATTACCGCGGCTGCTGGAA

- Consensus sequence (Forward + reverse):
272 bp

TCCTGTTTGATCCCCACGCTTTCGCACATCAGCGTCAGTTACAGACCAGAAAGTCGCCTTCGCCACTGGTGTTCCTCCATATCTCTGCGCATTTCACCGCTACACATGGAATTCCACTTTCCTCTTCTGCACTCAAGTTTTCCAGTTTCCAATGACCCTCCACGGTTGAGCCGTGGGCTTTCACATCAGACTTAAAAAACCGCCTACGCGCGCTTTACGCCCAATAATTCCGGATAACGCTTGCCACCTACGTATTACCGCGGCTGCTGGAA

The sequenced strain compared with the other sequenced bacteria in using BLAST tool in NCBI based on the in Gene- Bank and the $16 S$ ribosomal database, that showed similarity with some sequences belonging to the $16 \mathrm{~S}$ small subunit rDNA Staphylococcus aureus (KY007579).

\begin{tabular}{|c|c|c|c|c|}
\hline $\begin{array}{c}\text { Sequence } \\
\text { Accession }\end{array}$ & $\begin{array}{c}\text { Sequence } \\
\text { Length }\end{array}$ & $\begin{array}{c}\% \\
\text { Identical }\end{array}$ & Organism & $\% \mathrm{GC}$ \\
\hline KY007579 & 270 & $99.8 \%$ & $\begin{array}{c}\text { Staphylococcus } \\
\text { aureus }\end{array}$ & $51.9 \%$ \\
\hline KY176381 & 270 & $99.8 \%$ & $\begin{array}{c}\text { Staphylococcus } \\
\text { aureus }\end{array}$ & $51.9 \%$ \\
\hline
\end{tabular}

Top results obtained from BLAST search were downloaded in FASTA format and aligned with the isolate sequence using ClustalW method, in which an alignment of $271 \mathrm{bp}$ length was obtained, with zero differences (Fig. 4). 

Isolated From Pleural Fluid Identification of the active compounds

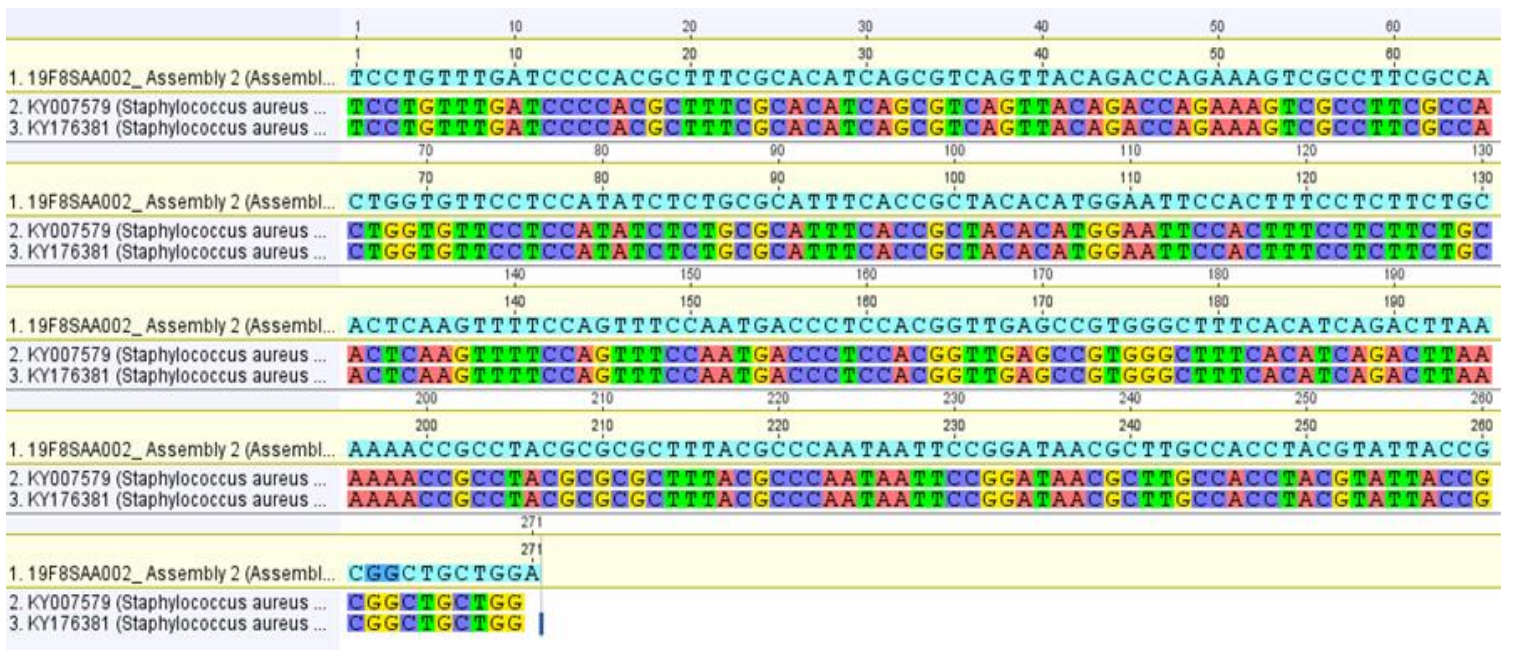

Fig. 4. Multiple sequence alignment of S.aureus partial nucleotide sequence of $16 \mathrm{~s}$ rDNA gene

The tree was generated using neighbor joining (NJ) a distance-based algorithm of phylogenetic analysis. Bacterial isolate (S.aureus P.F) was grouped with genus Staphylococcus. The sequence of $S$. aureus PF was most closely related to $S$. aureus accession number KY007579 and KY176381 with bootstrap support (confidence level) of $100 \%$ for both accessions Fig. (5).

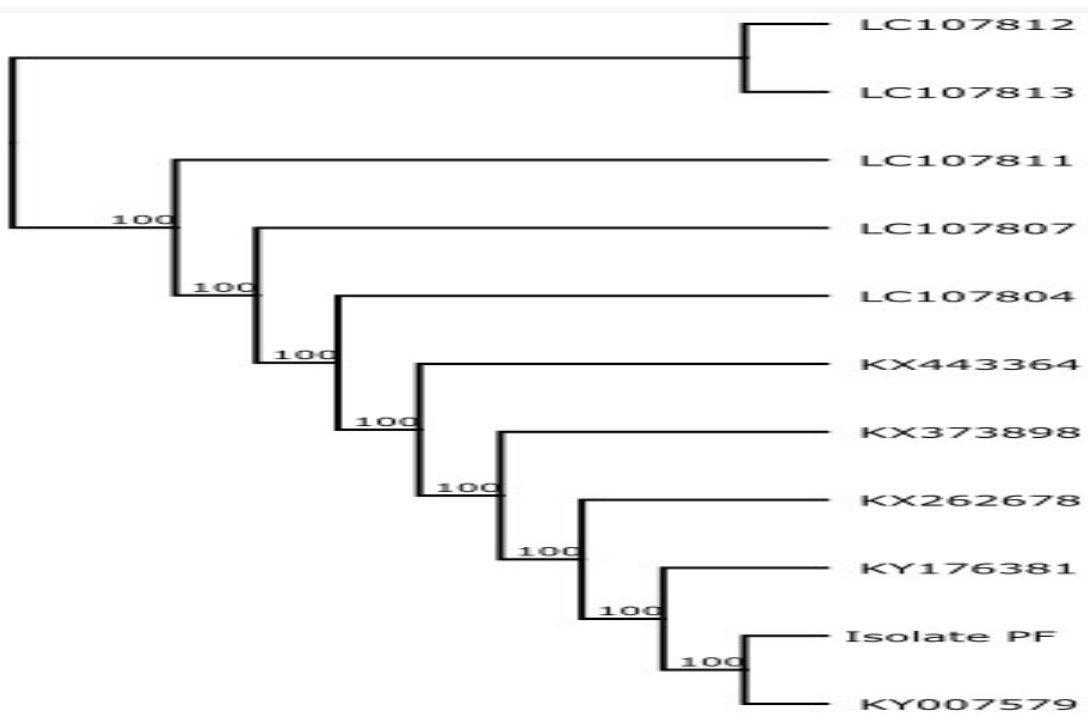

Fig. 5. Phylogenetic relation of S.aureus. The dendogram wa generated by the neighbor-joining method using BLASTn. 
Analysis of garlic essential oil by GC-MS spectrometry

Data presented in Table (4) showed the qualitative and quantitative analysis of hydro-distilled garlic essential oil sample which used in present investigation. GC-MS spectra dedicated that twenty-one compounds were identified and the major detected compounds were dominated to sulfur compounds. Diallyl disulphide (28.1784\%) and trisulfide, di-2-propenyl (27.128\%) were identified as major constituents. they are counting $55.3064 \%$ of total identified compounds. 3-(methylthio) penta2,4-dione (12.928\%), diallyl sulfide $(9.556 \%)$ and trisulfide, methyl-2-propenyl (7.851\%) and 1-allyl-3(2-(allylthio)propyl) trisulfane (3.223\%) were also identified. Those four compounds represent $33.558 \%$ of overall detected compounds. Chromatographic analysis quantitively showed that six sulfur compounds out of 21 represent $88.8644 \%$ of total detected compounds in garlic essential oil. Fig. (6) showed the GC chromatogram of garlic oil, Fig. (7), and Fig. (8) represented the MS spectra of six major sulfur compounds in garlic oil. While the allicin is the main constituent of allyl sulfide compounds in garlic oil and resulted from enzymatic conversion of alliin by allinase as presented in Schem I, allicin was not detected. This could be explained by the high instability of allicin under hydro-distillation conditions. Allicin instantly undergo degradation reactions resulted in different disulfide and trisulfide constituents Rainy et al (2014). Di and tri sulfides that were detected in garlic oil as major constituents in present report clearly confirmed the allicin presence.

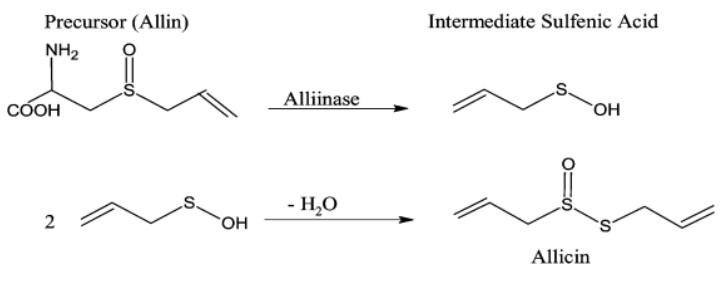

Schem I - Enzymatic conversion of Allin to Allicin, Bocchini et al (2001)

Depending on the previous investigation we can conclude that, (1) the main anti-microbial activity of garlic oil refers to allicin degradation products that were detected by GC-MS analysis, (2) It was not applicable to separate allicin by preparative chromatographic methods under regular analytical conditions to test its anti-microbial activity due to allicin instability. Dziri et al (2014) identified 17 components, covering more than $97 \%$ of the GC profiles of garlic oil extracted with different methods. Sulfur components group accounts for more than $84 \%$ of the total oil and was dominated by diallyl trisulfide (37.3-45.9\%), diallyl disulfide (17.5-35.6\%), methyl allyl trisulfide (7.7-10.4\%). the difference between obtained results and similar reports could be explained by the plant genotype and environmental factors that affect the garlic oil composition.

Table 4. Chemical constituents (\%) of garlic oil detected by GC-MS spectrometry

\begin{tabular}{|c|c|c|c|}
\hline & Retention & $\%$ & Compound name \\
\hline 1 & 4.9377 & 9.5559 & Diallyl sulfide \\
\hline 2 & 5.5808 & 1.8604 & Disulfide, methyl 2-propenyl \\
\hline 3 & 6.1166 & 1.2636 & Dimethyl trisulfide \\
\hline 4 & 6.7926 & 0.5942 & 1-Allyl-2-isopropyldisulfane \\
\hline 5 & 7.0441 & 28.1784 & Diallyl disulphide \\
\hline 6 & 7.1389 & 0.7841 & $\begin{array}{c}\text { (Z)-1-Allyl-2-(prop-1-en-1- } \\
\text { yl)disulfane }\end{array}$ \\
\hline 7 & 7.176 & 1.3564 & $\begin{array}{c}\text { (E)-1-Allyl-2-(prop-1-en-1- } \\
\text { yl)disulfane }\end{array}$ \\
\hline 8 & 7.4727 & 7.8507 & Trisulfide, methyl 2-propenyl \\
\hline 9 & 7.9674 & 0.3178 & $\begin{array}{c}\text { 3-Vinyl-1,2-dithiacyclohex-5- } \\
\text { ene }\end{array}$ \\
\hline 10 & 8.0045 & 0.3664 & Tetrasulfide, dimethyl \\
\hline 11 & 8.5238 & 27.128 & Trisulfide, di-2-propenyl \\
\hline 12 & 8.6434 & 0.3752 & $\begin{array}{c}\text { (Z)-1-Allyl-3-(prop-1-en-1- } \\
\text { yl)trisulfane }\end{array}$ \\
\hline 13 & 9.8387 & 12.9281 & 3-(Methylthio)penta-2,4-dione \\
\hline 14 & 10.0531 & 0.414 & 2-Pentanone, 5-(trimethylsilyl)- \\
\hline 15 & 10.4076 & 0.4206 & Cyclic octaatomic sulfur \\
\hline 16 & 10.8404 & 0.9795 & 5-Ethylthiazole \\
\hline 17 & 10.9558 & 0.5848 & $\begin{array}{c}\text { Hexanoic acid, 2-ethyl-, hexa- } \\
\text { decyl ester }\end{array}$ \\
\hline 18 & 11.0918 & 3.2227 & $\begin{array}{c}\text { 1-Allyl-3-(2- } \\
\text { (allylthio)propyl)trisulfane }\end{array}$ \\
\hline 19 & 11.5288 & 0.4222 & 2-Nitrophenyl-azo-thio-thiol \\
\hline 20 & 12.6664 & 0.4691 & Octadecane \\
\hline 21 & 13.293 & 0.9279 & Octadecane \\
\hline
\end{tabular}




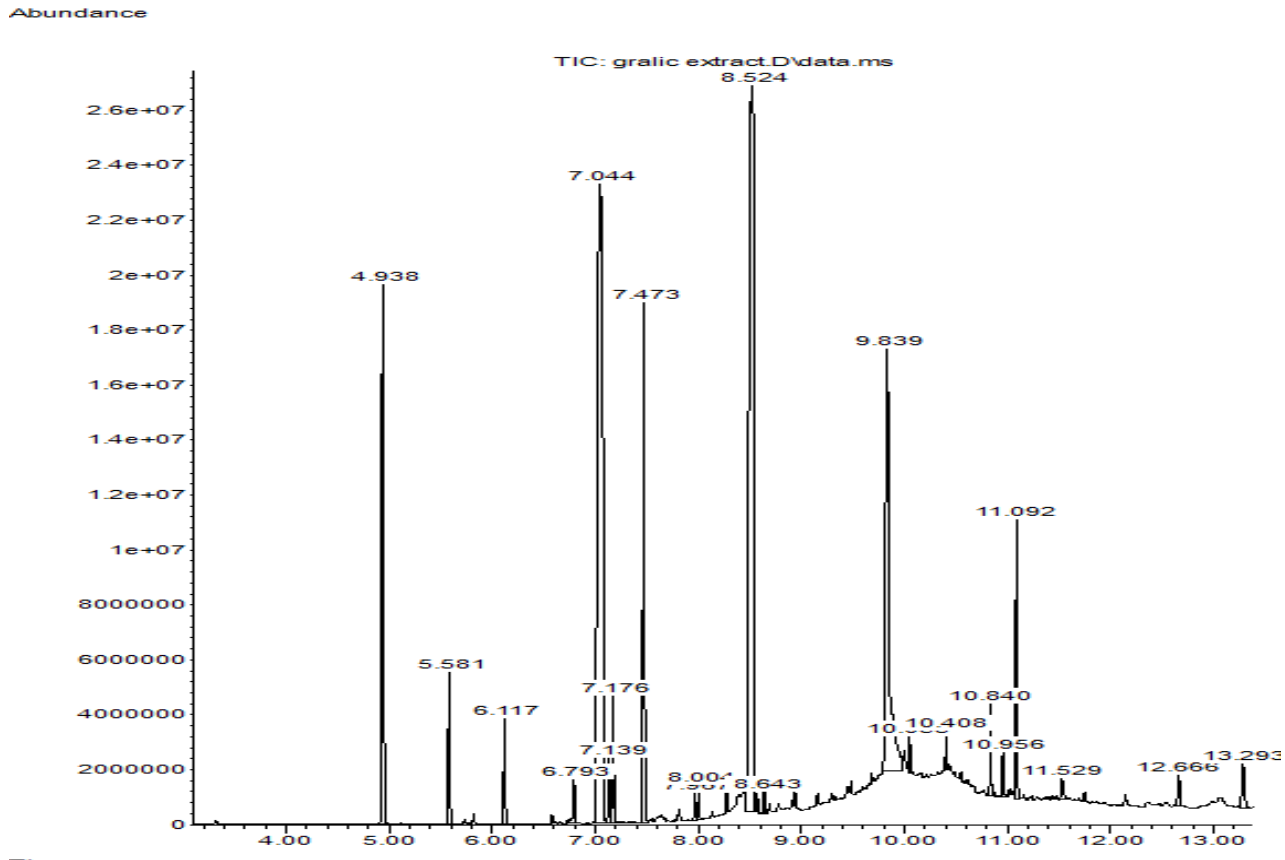

Fig. 6. GC Chromatogram of garlic oil
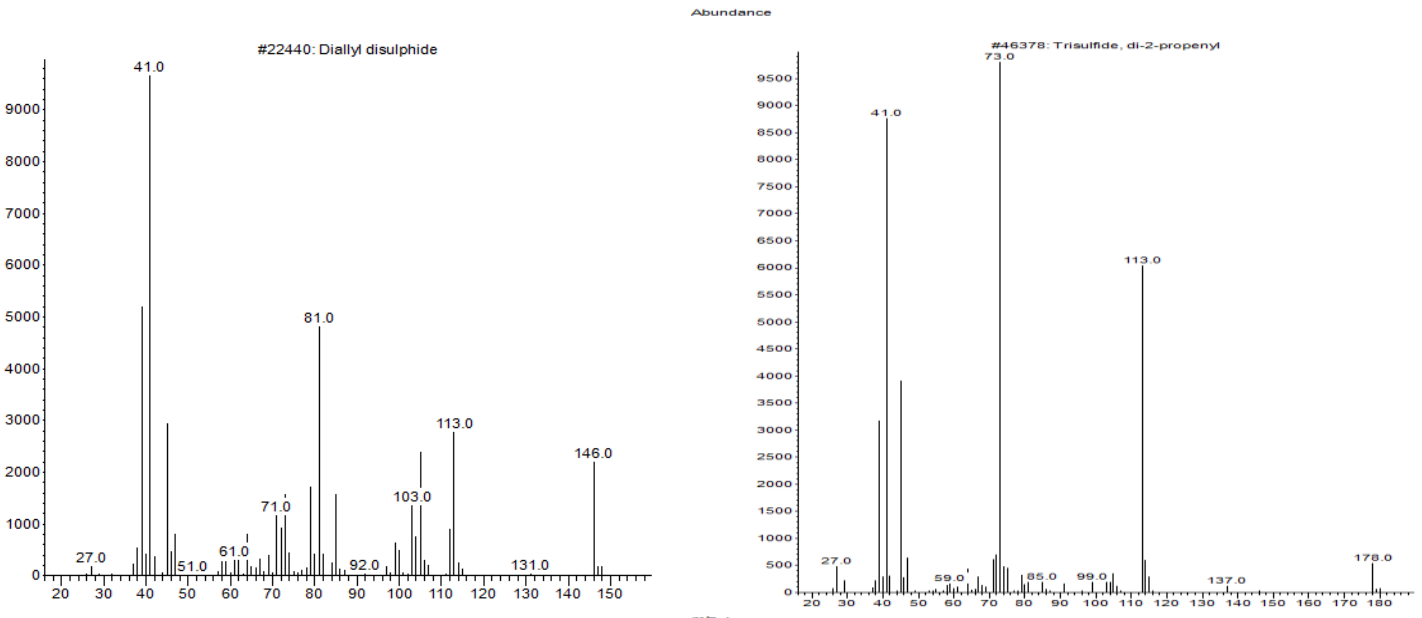

Fig. 7. MS spectrum of diallyl disulphide (M.W. 146) $28.178 \%$ (left), and trisulfide, di-2-propenyl (M.W. 178) $27.128 \%$ (right). 

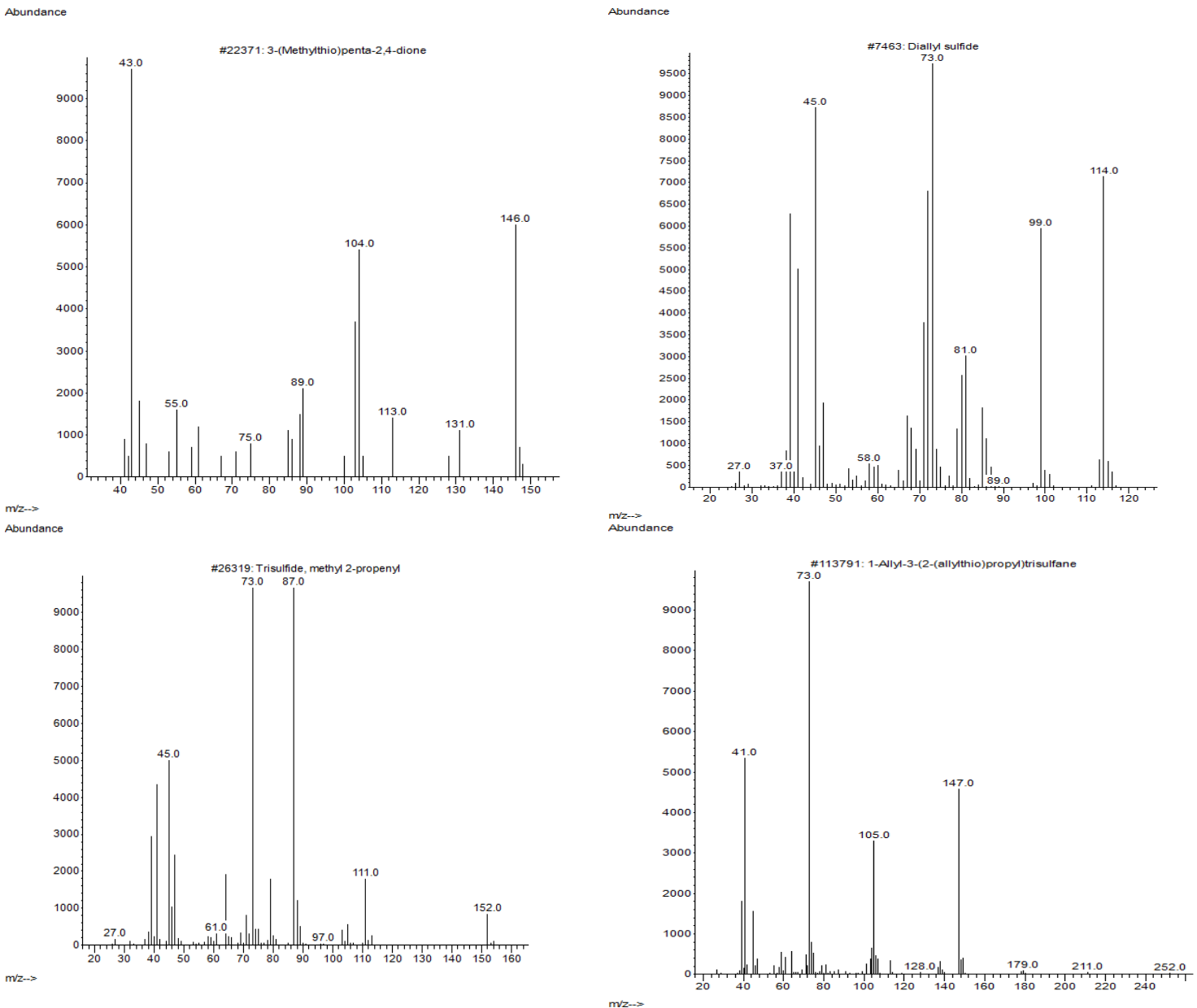

Fig. 8. MS spectrum of 3-(Methylthio)penta-2,4-dione (M.W. 146) 12.928\% (top left), diallyl sulfide (M.W. 114) $9.556 \%$ (top right), Trisulfide, methyl 2-propenyl (M.W. 152) 7.851\% (down left) and 1-Allyl-3-(2(allylthio)propyl)trisulfane (M.W. 147) 3.223\%(down right).

\section{REFERENCE}

Abu-Shanab, B., Adwan, G., Jarrar, N., AbuHijli, A. and Adwan, K. 2006. Antibacterial activity of four plant extracts used in Palestine in folkloric medicine against methicillin-resistant Staphylococcus aureus. Turkish J. of Biology. 30, 195-198.

Adams, R. 2001. Identification of Essential Oil Components by Gas Chromatography/ Quadrupole Mass Spectroscopy. $4^{\text {th }}$ ed. Allured Publ. Corp, Carol Stream, 804 p.

Ali, M.R. and Aboud A.S. 2010. Antimicrobial Activities of Aqueous and Methanolic Extracts from Salvia officinalis and Salix acmophylla Used in the treatment of wound infection isolates. IBN Al-haitham J. for Pure \& Appl. Sci., 23(3), 1-14.
Alli, J.A., Boboye, B.E., Okonko, I.O., Kolade A.F. and Nwanze, J.C. 2011. In-vitro assessments of the effects of garlic (Allium sativum) extract on clinical isolates of Pseudomonas aeruginosa and Staphylococcus aureu. Adv. Appl. Sci. Res., 2(4), 25-36.

APHA (American Public Health Association) 1992. Compendium of methods for microbiological examination of foods $2^{\text {nd }}$ ed. American Public Health Association, Washington, DC, USA. pp. 633-681.

Baird-Parker, A.C. 1962. An improved diagnostic and selective medium for isolating coagulasepositive staphylococci. J. Appl. Bacteriol. 25, 12-19.

Barbour, E.K., Al-Sharif, M., Sagherian, V.K., Habre, A.N., Talhouk, R.S. and Talhouk, S.N. 
2004. Screening of selected indigenous plants of Lebanon for antimicrobial activity. J. of Ethnopharmacology 93, 1-7.

Bayoub, K., Baibai T., Driss M., Abdelaziz, R. and Abdelaziz, S. 2010. Antibacterial activities of the crude ethanol extracts of medicinal plants against Listeria monocytogenes and some other pathogenic strains. African J. of Biotechnology, 9(27), 4251-4258.

Bocchini, P., Andalò, C., Pozzi, R., Galletti G.C. and Antonelli, A. 2001. Determination of diallyl thiosulfinate (allicin) in garlic (Allium sativum L.) by high-performance liquid chromatography with a post-column photochemical reactor. Analytica Chimica Acta., 441, 37-43.

Bonjar, G.H.S. 2004. Evaluation of antibacterial properties of Iranian medicinal plants against Micrococcus luteus, Serratia marcescens, Klebsiella pneumoniae and Bordetella bronchoseptica. Asian Journal of Plant Sci., 3, 8286.

Braga, L.C., Leite, A.A.M., Xavier, K.G.S., Takahashi, J.A., Bemquerer, M.P., ChartoneSouza, E. and Nascimento, A.M.A. 2005. Synergic interaction between pomegranate extract and antibiotics against Staphylococcus aureus. Can. J. Microbiol., 51, 541-547.

Cappuccino, J.G. and Sherman, N. 1996. Microbiology: A laboratory Manual. $4^{\text {th }}$ ed. The Binjamin/Cummings Publishing Company. Inc. Californai. USA. 477 p.

Christensen, G.D., Simpson, W.A., Bisno, A.I. and Beachey, E.H. 1982. Adherence of slimproducing strains of Staphylococcus epidermidis to smooth surfaces, Infection and Immunity, 37, 318-326.

Darwish, R.M., Aburjai, T., Al-Khalil, S. and Mahafzah, A. 2002. Screening of antibiotic resistant inhibitors from local plant materials against two different strains of Staphylococcus aureus. J. of Ethnopharmacology. 79, 359364.

Davidson, P.M. and Parish, M.E. 1989. Methods for testing the efficacy of food antimicrobials. Food Technol. 43, 148-155.

De Boer, H.J., Kool, A., Broberg, A., Mziray, W.R., Hedberg, I. and Levenfors J.J. 2005. Antifungal and antibacterial activity of some herbal remedies from Tanzania. J. Ethnopharmacol 96, 461-9.

Derrida, M. 2003. What is bitter melon (Momordica charantia). http://www.brama.com/ business/messages/40688.html.
Dziri Salma, Hervé Casabianc, Belgacem Hanchi and Karim Hosni 2014. Composition of garlic essential oil (Allium sativum L.) as influenced by drying method. J. of Essential Oil Research 26(2), 91-96.

Eja, M.E., Asikong, B.E., Abriba, C., Arikpo, G.E., Anwan, E.E. and Enyi-Idoh, K.H. 2007. A comparative assessment of the antimicrobial effects of garlic (Allium sativum) and antibiotics on diarrheagenic organisms. Southeast Asian J. Trop. Med. and Public Health, 38(2), 344348.

Esimone, C.O., Iroha, I.R., Ibezim, E.C., Okeh, C.O. and Okpana, E.M. 2006. In vitro evaluation of the interaction between tea extracts and penicillin G. against staphylococcus aureus. Afr. J. Biotechnol 5, 1082-1086.

Gislene, G.F.N., Juliana L., Paulo C.F. and Giuliana L.S. 2000. Antibacterial Activity of Plant Extracts and Phytochemicals on AntibioticResistant Bacteria. Brazilian J. of Microbiology, 31, 247- 256.

Greenberg. J., Simon, L., Harmon-Jones, E., Solomon, S., Pyszczynskt, T. and Lyon, D. 1995. Testing alternative explanations for mortality salience effects: terror management, value accessibility, or worrisome thoughts, European J. of Social Psychology, 25, 417-433.

Groppo, F.C., Ramacciato, J.C., Simoes, R.P., Florio, F.M. and Sartoratto A. 2002. Antimicrobial activity of garlic, tea tree oil and chlorhexidine against oral microorganism. Int. Dent. J., 52, 433- 437.

Gupta, C., Garg, A.P., Uniyal, R.C. and Gupta, S., 2009. Comparison of Antimicrobial Activities of Clove Oil \& Its Extract on Some Food Borne Microbes. The Int. J. of Microbiology, 7(1), 17.

Hossain, M.D. Towhid and Uddin, M.D. Kamal 2014. Optimization of culture condition for a biofilm forming bacterium. Int. J. Pharm Bio. Sci., 5(1), $11-20$.

Huggan, P.J., Murdoch, D.R., Gallagher, K. and Chambers, S.T. 2008. Concomitant Staphylococcus aureus bacteriuria is associated with poor clinical outcome in adults with $S$. aureus bacteraemia. J. Hosp Infect. 69, 345-9.

Koneman, E.W., Allen, S.D., Janda, W.M., Schreckenberger, P.C. and Winn, W.C. 1997. The Enterobacteriaceae. In: Color Atlas and Textbook of Diagnostic Microbiology, Baltimore, L.W.W. $5^{\text {th }}$ ed., JB Lippincott Co., Philadelphia, pp. 171-230. 
Lambert, R.J.W., Skandamis, P.N., Coote, P.J. and Nychas, G.J. 2001. A study of mininmum inhibitory concentration and mode of action of oregano essential oil, thymol and carvacrol. J. Appl. Microbiol. 91, 453-462.

Lemar, K.M., Passa, O., Aon, M.A., Cortassa, S., Müller, C.T., Plummer, S., O'Rourke, B. and Lloyd, D. 2005. Allyl alcohol and garlic (Allium sativum) extract produce oxidative stress in Candida albicans. Microbiology 151, 32573265.

Mackie, and McCartney, 1996. Practical Medical Microbiology. $4^{\text {th }}$ ed., New York, Churchill Livingstone, $978 \mathrm{p}$.

Mahady, G.B. 2001. Global harmonization of herbal health claims. J. of Nutrition, 131, 1120-1123.

Mahdi, K.M., Mohammad, Y., Mohammad, R. and Mansour, G. 2013. Study on antibacterial effect of thyme and peppermint aqueous extracts on Staphylococcus aureus and Escherichia coli strains causing mastitis in Camels. Int. J. of Traditional and Herbal Medicine. 1(4), 112-115.

Marioara, N.F., Aurica, B.B. and Smaranda, L.G. 2009. Testing the sensitivity of Staphylococcus aureus antibiotics. Tom. XVI/ 2, 70-73.

Monika, S., Anna, G., Katarzyna, P.K., Andrzej K., Anna, U. and Edward, K. 2015. The effect of clary sage oil on staphylococci responsible for wound infections, Postępy Dermatologii Alergologii, 32(1), 21-26.

Mueller, J.H. and Hinton, J. 1941. A protein- free medium for primary isolation of gonococcus and meningococcus. Proceedings of the Society for Experimental Biology and Medicine, 48, 3330-3333.

Nair, R., Kalariya, T. and Chanda, S. 2005. Antibacterial activity of some selected Indian medicinal flora. Turkish J. of Biology. 29, 41-7.

Nascimento, G., Locatelli, P., Freitas, C. and Silva, G. 2000. Antibacterial Activity of Plant Extracts and Phytochemicals on Antibiotic resistant Bacteria. Brazilian J. of Microbiology, 31, 247-256.

NCCLS (National Committee for Clinical Laboratory Standards) 1993. Performance Standards for Antimicrobial Disc Suspectibility Tests. Approved Standard NCCLS Publication, Villanova, PA, USA, 35, 1-73.
NCCLS (National Committee for Clinical Laboratory Standards), 2008. Performance Standards for Antimicrobial Suspectibility Testing; ninth informational supplement; NCCLS document M 100-59; pp. 120-126.

Nzeako, B.C., Zahra, S.N. Al-Kharousi, and Zahra Al-Mahrooqui 2006. Antimicrobial Activities of Clove and Thyme Extracts. Sultan Qaboos Univ., Med. J. Jun; 6(1), 33-39.

Parekh, J., Jadeja, D. and Chanda S. 2005. Efficacy of Aqueous and Methanol Extracts of Some Medicinal Plants for Potential Antibacterial Activity. Turk J. Bio 29, 203-210.

Poorani, E., Saseetharan, M. and Dhevagi, P. 2009. L-asparaginase production and molecular identification of marine Streptomyces spstrain EPD 27. Int. J. Integr. Biol., 7(3), 150155.

Proestos, C., Boziaris, I.S., Ny Chas, G.J.E. and Komaitis, M. 2006. Analysis of flavonoids and phenolic acids in Greek aromatic plants: Investigation of their antioxidant capacity and antimicrobial activity. Food Chemistry. 95, 664-671.

Rainy, G., Sharma, A., Maina, P. and Shukla, R.N. 2014. Study of chemical composition of garlic oil and comparative analysis of cotrimoxazole in response to in vitro antibacterial activity. Int. Res. J. Pharms. 5(2), 79-101.

Tadeg, H., Mohammed, E., Asres, K. and GebreMariam, T. 2005. Antimicrobial activities of some selected traditional Ethiopian medicinal plants used in the treatment of skin disorders. J. Ethnopharmacol, 100(1-2), 168-75.

Uzun, E., Sariyar, G., Adsersen, A., Karakoc, B., Otuk, G., Oktayoglu, E. and Pirildar, S. 2004. Traditional medicine in Sakarya province (Turkey) and antimicrobial activities of selected species. J. of Ethnopharmacology, 95, 287296.

WHO (World Health Organization), 2001. General guidelines for methodologies on research and evaluation of traditional medicine. WHO, Geneva, Switzerland, 74 p.

Yang, Z.C., Wang, B.C., Yang, X.S., Wang, Q. and Ran, L. 2005. The synergistic activity of antibiotics combined with eight traditional Chinese medicines against two different strains of Staphylococcus aureus. Colloids Surf B Biointerfaces, 41, 79-81. 